\title{
Possibilities of the Quantitative Comparison of Catalytic Capacity in Autocatalytic Processes of Palladium- Containing Nanocatalysts
}

\author{
Zulayho A. Smanova, National University of Uzbekistan, Uzbekistan \\ Tokhir Kh. Rakhimov, National University of Uzbekistan, Uzbekistan \\ (iD) https://orcid.org/0000-0002-5755-5918 \\ Muxtarjan Mukhamediev, National University of Uzbekistan, Uzbekistan \\ Dilfuza A. Gafurova, National University of Uzbekistan, Uzbekistan \\ Dilbar A. Shaxidova, National University of Uzbekistan, Uzbekistan
}

\begin{abstract}
When studying the nanocrystalline state, in some cases, an increase in functional activity is observed with an increase in the size of nanoparticles. In this case, the most active atoms are situated on the faces and have a higher coordination in comparison with the atoms on the tops and the edges. One of the explanations for this phenomenon is the formation of hypercycles due to the occurrence of autocatalytic processes. For oscillatory processes inherent in autocatalysis, when the parameters of a nonequilibrium process change over time, it is difficult to apply traditional methods of processing the results of analytical studies. In this regard, it is necessary to develop a methodology for a comparative study of short-term parameters of processes on the same scale, highlighting the main ones and eliminating insignificant and random ones, such as the phase shift at the beginning of selfoscillations or time-localized deviations from activity. This paper presents the results of such a study on the example of palladium-containing nanosystems in the reaction of low-temperature oxidation of CO. It is shown that the study of the behavior of nanocatalysts during the formation of hypercycles is informative using the calculated generalized parameters of the process
\end{abstract}

\section{KEYWORDS}

Carbon Fiber Materials, Carbon Monoxide, Catalysts, Mathematical Modeling, Nanocrystalline, Nanoparticle Size, Nanosystems, Oxidation, Palladium, Size Effect

\section{INTRODUCTION}

The high activity of nanoparticles is explained by electron and geometric effects, although this division is very conventional because both effects have the same source, that is, a small particle size (Kempkes et al., 2019, Anwar et al, 2019, Zhizhin 2019). Obviously, there is also a lower activity limit, usually exceeding approximately the cluster size, i.e. a region of optimal size is always observed, 
within which the activity of nanoparticles is maximum. The relationship between size and activity is the most intriguing area of nanosystem science (Casañola-Martin, 2019). Of particular interest is the question of the upper boundary of particle sizes. It is believed that the main scope of investigations in this area is to determine the critical particle size, below which the characteristic properties of nanocrystals become observable, and above which the material behaves like a bulk material (Gusev et al., 2004, Rasulev et al, 2012). The previously proposed method for determining the boundary dimensions, based on serial experiments and the use of methods of mathematical statistics - "model of balls coloring" (Rakhimov et al., 2019) made it possible to determine that in some cases the upper limit is significant - from $100 \mathrm{~nm}$ to half a micron. In particular, this phenomenon is observed in the study of the oxidation of carbon monoxide with oxygen.

Since the geometric effect of catalysis depends on the ratios of the number of atoms distributed on the faces, on the edges and tops of the nanoparticle, we can say that in these cases the atoms on the faces with a higher coordination are more active than the atoms on the vertices and edges. Therefore, the rate of the catalysed reaction will be increased by the larger particles. It is shown theoretically that in this case the behavior of ensembles with the formation of hypercycles is possible, when oxidation is realized by waves of self-oscillations (Kalgin, 2011). However, these phenomena have not been sufficiently studied experimentally. It can be assumed that the main obstacles in this are methodological in nature. In this paper, we attempted to use the measurement of "instantaneous" values of catalytic activity to hypercycles' study.

\section{RESULTS AND DISCUSSIONS}

The study of the catalytic properties of palladium-containing nanocatalysts in the reaction of lowtemperature $\mathrm{CO}$ oxidation showed a clear presence of oscillations (Figure 1), when catalytically active structures are formed after exposure to the substrate for a certain time, i.e., a phenomenon called "training" of the catalyst is observed (Bol'shakov et al., 2001). Since according to J. Von Neumann (Von\&Burks 1996) the ability to reproduce itself depends fundamentally on the complexity of the organization, and there is a well-defined critical level of complexity, starting from which it becomes self-sustaining or even can grow (Kureychik et al., 2007). In this case, the ability to train indicates a high probability of the formation of catalytic hypercycles (Gorovoy 2018) i.e., systems in which autocatalytic (i.e., self-reproducing) units are, in turn, interconnected through cyclic communication. Scientific interest in such processes is constantly growing, starting with the works of Prigogine, but despite this, there are practically no studies on the study of hypercycle structures for specific autocatalytic reactions.

It is reasonable to assume that one of the stumbling blocks is the lack of a developed methodology for the comparative study of "instantaneous" characteristics of autocatalytic processes, in particular, for processing measurement results (Mukhamediev et al., 2015).

Autocatalysis during oxidation with oxygen is not always manifested, and this depends on the nature of the catalyst carrier, its structure and heterogeneity. Thus, autocatalysis is observed in some cases with the use of some crystalline carriers-chromium oxide, alumochrome, as well as some polymer fibers (activated carbon fibers), but in most cases there is a reduction of palladium ions to metal with the oxidation of CO to dioxide (Rakhimov et al., 2014). The method of application of the active component, the state and availability of surface-active nanoparticles, the location of active centers (for example, on the faces or edges of nanocrystals); the presence of inhibitors and promoters, including those formed or desorbed from the carrier; temperature, pressure, flow rate and its laminarity/turbulence, etc. are also important.

A number of factors have a random character, which is not related to the measurement error, but is fundamentally unavoidable, due to the nature of the functionality of the nanostructures themselves.

Autocatalysis during oxidation with oxygen does not always manifest itself, and this depends on the nature of the catalyst support, its structure, and heterogeneity. Thus, autocatalysis is observed in 


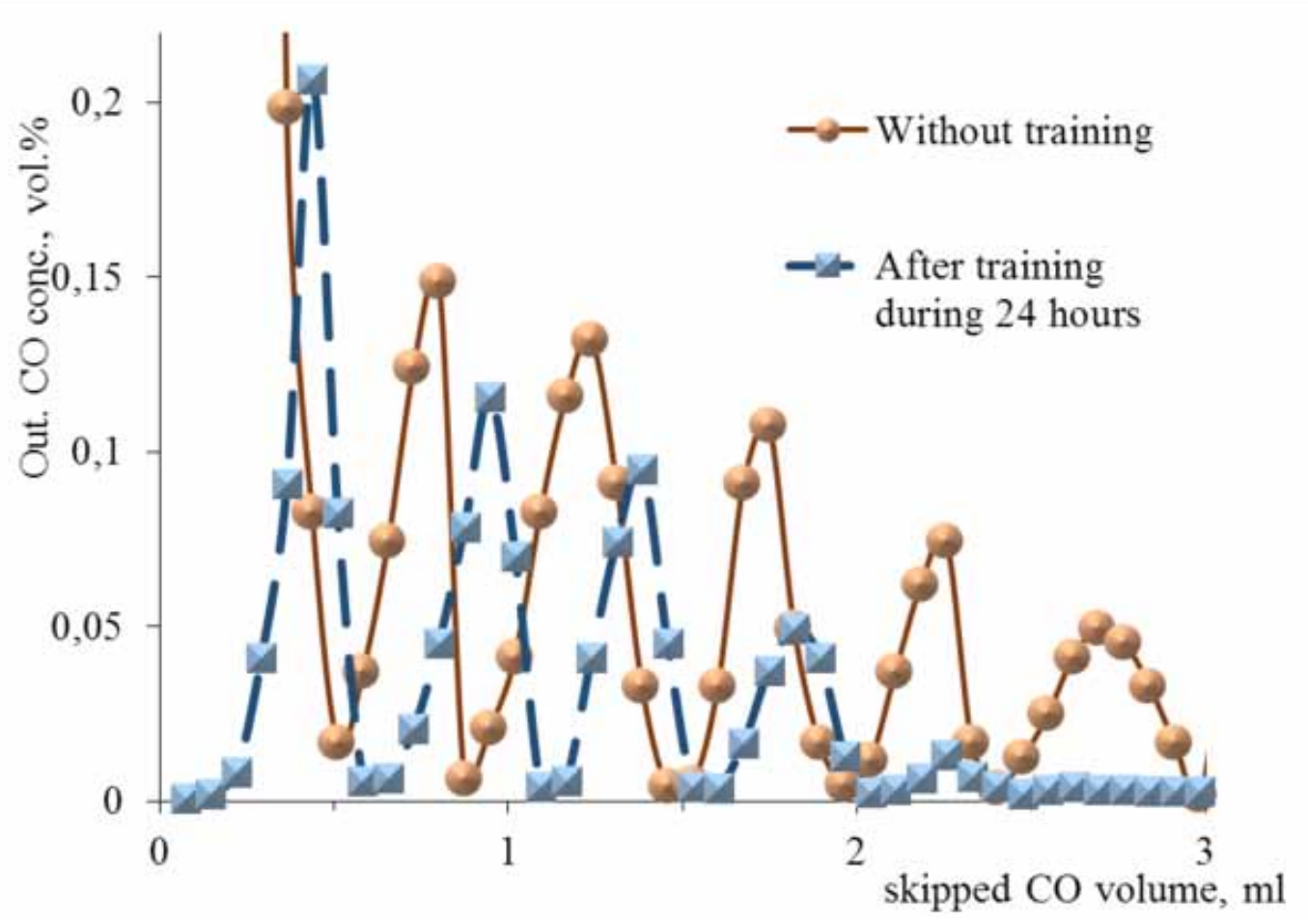

some cases when using some crystalline carriers - chromium oxide, alumochromium, as well as some polymer fibers (activated carbon fibers), but in most cases, palladium ions are reduced to metal with CO oxidation to dioxide (Rakhimov et al., 2014). The method of applying the active component, the state and presence of surface-active nanoparticles, the location of active centers (for example, on the edges or edges of nanocrystals); the presence of inhibitors and promoters, including those formed or desorbed from the carrier; temperature, pressure, flow rate and its laminarity / turbulence, etc. are also important.

For comparison, palladium-containing nanostructures on $\alpha-\mathrm{A} 12 \mathrm{O} 3$ were studied. In the presence of these structures, the $\mathrm{CO}$ oxidation reaction proceeds without oscillations with a gradual decrease in the rate. In this case, the calculated boundary dimensions were from 2 to $8 \mathrm{~nm}$. Furthermore we calculated the boundary sizes of nanosystems based on the literature data (Shulgina, 2015) using the model of balls coloring. Calculations showed that the antimicrobial activity of nanosystems is manifested in iron particles with diameters from 5 to $14 \mathrm{~nm}$, and in zinc nanoparticles - from 6 to $9 \mathrm{~nm}$.

Thus, in the absence of oscillations, the boundary dimensions are calculated based on the data on the activity of a series of mutually similar samples. However, during the autocatalytic process, the activity boundaries should also shift, which introduces additional uncertainty. Therefore, for a comparative study of nanosystems, we used data on the initial activity, i.e. at the point of intersection of the self-oscillation curve with the ordinate axis (Figure 1).

The increase in activity when exposed to $\mathrm{CO}$ for a certain time (line "Without training", Figure 1) may be the result of the reductive effect of $\mathrm{CO}$ on palladium ions. However, other explanations are also possible, for example, complexation. To experimentally verify the assumption about the key role of recovery, special experiments were carried out. A series of several samples was synthesized, differing only in the sizes of nanoparticles. Then each of the samples was divided into 10 parts. Each 
Table 1. Measurements of the $\mathrm{CO}$ concentration at the output after passing through a reactor with palladium-containing nanoparticles deposited on aluminum $\alpha$-oxide. WITH 2.0 vol. $\%, 25^{\circ} \mathrm{C} 2 \% \mathrm{Pd}$, based on the metal.

\begin{tabular}{|l|l|l|l|l|l|l|}
\hline $\begin{array}{l}\text { Volume of } \\
\text { skipped } \text { CO, } l\end{array}$ & experience 1 & experience 2 & experience 3 & experience 4 & Average & Dispersion \\
\hline $\mathbf{0}$ & 0 & 0 & 0 & 0 & 0,000 & 0,000 \\
\hline $\mathbf{0 , 1}$ & 0,011 & 0,012 & 0,016 & 0,014 & 0,013 & 0,002 \\
\hline $\mathbf{0 , 2}$ & 0,019 & 0,022 & 0,027 & 0,024 & 0,023 & 0,003 \\
\hline $\mathbf{0 , 3}$ & 0,049 & 0,055 & 0,056 & 0,054 & 0,054 & 0,003 \\
\hline $\mathbf{0 , 4}$ & 0,197 & 0,211 & 0,206 & 0,204 & 0,205 & 0,006 \\
\hline $\mathbf{0 , 5}$ & 0,488 & 0,512 & 0,509 & 0,522 & 0,508 & 0,014 \\
\hline $\mathbf{0 , 6}$ & 1,17 & 1,204 & 1,02 & 0,221 & 0,904 & 0,462 \\
\hline $\mathbf{0 , 7}$ & 2,62 & 2,707 & 2,721 & 3,02 & 2,767 & 0,174 \\
\hline $\mathbf{0 , 8}$ & 6,64 & 7,111 & 6,824 & 6,22 & 6,699 & 0,373 \\
\hline
\end{tabular}

part was exposed to a metered amount of hydrogen. Then the initial activity was measured and the boundary dimensions were calculated at the initial stage of the reaction. The data show that dosed reduction to a certain extent increases the catalytic activity and shifts the boundaries of functionality to the region of large diameters (Figure 2).

For correct comparison and finding patterns, an increase in a small sample is used, i.e. a large number of experiments performed with equal controlled parameters. A comparative study of the oxidative capacity is convenient to carry out in the flow mode. However, it provides only averaged indicators, which makes it impossible to study the process in detail. The instantaneous values of the $\mathrm{CO}$ concentration, on the basis of which the catalytic activity is calculated, in the autocatalytic $\mathrm{CO}$ oxidation reaction change vibrationally. These values were measured in the pulse mode (Rakhimov et al., 2015). Which can provide information about the current state of the system, provided that in the absence of a substrate, there are no significant changes in it.

As mentioned above, most palladium-containing nanocrystallites do not exhibit autocatalytic properties and, accordingly, are oxidized by reducing palladium ions to metal (Table 1).

The standard deviation is calculated by the formula: $\sqrt{\frac{\sum(x-\bar{x})^{2}}{n-1}}$, where $\mathrm{x}$ is the sample mean (number1, number $2, \ldots$ ), and $\mathrm{n}$ is the sample size. The most reproducible results were observed in the deposited palladium-containing composites on gamma-aluminum oxide. In the same conditions they were detective reverse through an equal length of time (Figure 2).

A six-fold repetition of the test confirms the reliability of the results obtained. Mathematical processing confirms a high degree of reproducibility and a high degree of correlation between experiments (Table 2).

The reaction profile is described by a polynomial of the fifth degree, in particular, under the given conditions, it is described by the equation: $y=204.49 x^{5}-311.6 x^{4}+177.3 x^{3}-40.344 x^{2}+$ 3.0775x - 0.0083. with high accuracy of the approximation, $R^{2}=0.999$

This means that the total error resulting from errors in measuring equipment and methods for determining concentrations is negligible. 
Figure 2. Upper and lower boundaries of the fractions of nanoparticles exhibiting catalytic activity after metered exposure to hydrogen. The curve shows the initial activity value.

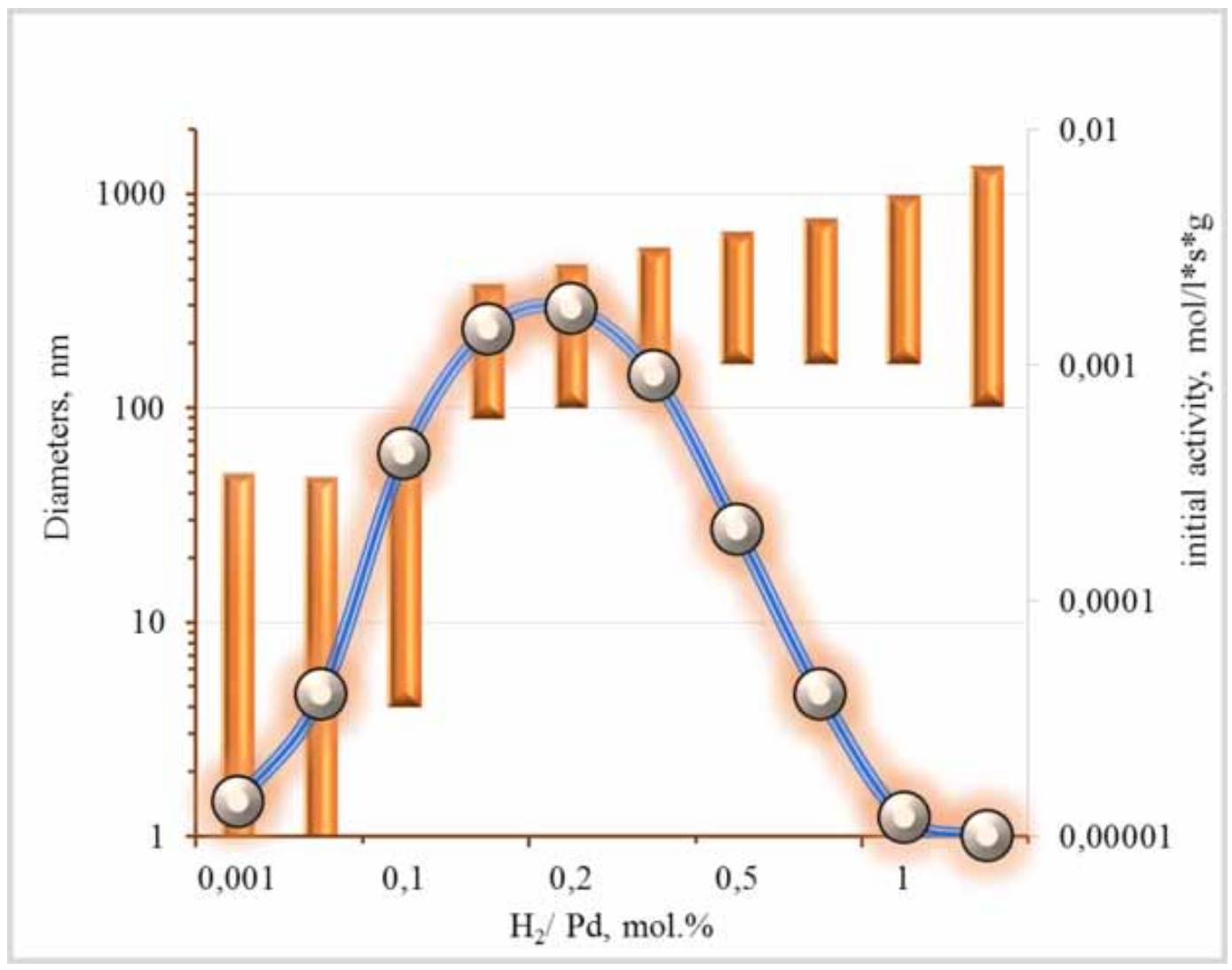

\section{Catalytic processes}

For oscillatory reactions (Figures 3-4), the degree of correlation is much less. Confidence intervals are calculated for a probability of $68 \%$, but also reach up to $85 \%$ of the average value (Tables 3-4). In experiments, the residual volume concentration of $\mathrm{CO}, \mathrm{C} \% * 100$, was measured.

Low reproducibility once again confirms that oscillatory reactions are highly sensitive, poorly controlled factors can have a significant impact on the course of the process. In this case, you can see how the frequency of self-oscillations changes, which introduces a significant error in the definition.

However, in fact, the mode provides reliable information about the most important thing - that the catalysts on chromium oxide work stably after training in oscillatory mode, and on alpha-aluminum oxide-are deactivated.

Mathematical processing in the form of regression analysis of the determination methods confirmed the literature data, the error is from $2 \%$ for high concentrations to $25 \%$ for concentrations below $1 \mathrm{mg} / \mathrm{m} 3$. Analysis of the data obtained in the flow and circulation modes showed better reproducibility than in the pulse mode. The worst result with a confidence probability of $68 \%$ did not exceed $25 \%$ of the average.

Thus, mathematical statistics confirmed the reliability and repeatability of the results of complex tests in the modes used in this study. The autocatalytic reaction mechanism introduces an error due to the high sensitivity of the process. 
Table 2. Mathematical processing and descriptive statistics for repeated measurements of the activity of a palladium composite on aluminum $\alpha$-oxide in the $\mathrm{CO}$ oxidation reaction

\begin{tabular}{|c|c|c|c|c|c|c|c|c|c|c|}
\hline \begin{tabular}{l|l}
$\begin{array}{l}\text { Volume of } \\
\text { skipped }\end{array}$ & 0 \\
$\mathrm{CO}, l$ &
\end{tabular} & 0,1 & 0,2 & 0,3 & 0,4 & \multicolumn{2}{|l|}{0,5} & \multicolumn{2}{|l|}{0,6} & 0,7 & 0,8 \\
\hline & \multicolumn{10}{|c|}{ CO concentration at the output, vol. $\% * 100$} \\
\hline \begin{tabular}{l|l} 
experience & 0 \\
1 &
\end{tabular} & 0,01 & 0,02 & 0,05 & 0,2 & \multicolumn{2}{|l|}{0,5} & \multicolumn{2}{|l|}{1,2} & 2,7 & 6,8 \\
\hline \begin{tabular}{l|l} 
experience & 0 \\
2 &
\end{tabular} & 0,014 & 0,021 & 0,06 & 0,3 & \multicolumn{2}{|l|}{0,6} & \multicolumn{2}{|l|}{1,3} & 2,8 & 7,18 \\
\hline \begin{tabular}{l|l} 
experience & 0 \\
3 &
\end{tabular} & 0,02 & 0,024 & 0,04 & 0,4 & \multicolumn{2}{|l|}{0,4} & \multicolumn{2}{|l|}{1,8} & 3,5 & 5,11 \\
\hline \begin{tabular}{l|l} 
experience & 0 \\
4 &
\end{tabular} & 0,01 & 0,022 & 0,04 & 0,3 & \multicolumn{2}{|l|}{0,4} & \multicolumn{2}{|l|}{1,01} & 2,07 & 9,01 \\
\hline \begin{tabular}{l|l} 
experience & 0 \\
5 &
\end{tabular} & 0,012 & 0,024 & 0,05 & 0,3 & \multicolumn{2}{|l|}{0,72} & \multicolumn{2}{|l|}{1,04} & 4,12 & 8,04 \\
\hline \begin{tabular}{l|l} 
experience & 0 \\
6 &
\end{tabular} & 0,011 & 0,023 & 0,061 & 0,28 & \multicolumn{2}{|l|}{0,66} & \multicolumn{2}{|l|}{1,4} & 3,11 & 7,12 \\
\hline $\begin{array}{l}\text { The average } \\
\text { value }\end{array}$ & 0,0128 & 0,0241 & 0,0502 & 0,2967 & \multicolumn{2}{|l|}{0,5467} & \multicolumn{2}{|l|}{1,2917} & 3,0500 & 7,2100 \\
\hline Standard error & 0,0016 & 0,0019 & 0,0037 & 0,0260 & \multicolumn{2}{|l|}{0,0551} & \multicolumn{2}{|l|}{0,1185} & 0,2885 & 0,5328 \\
\hline The median & 0,0115 & 0,0230 & 0,0500 & 0,3000 & \multicolumn{2}{|l|}{0,5500} & \multicolumn{2}{|l|}{1,2500} & 2,9550 & 7,1500 \\
\hline Mode & 0,0100 & 0,0240 & 0,0500 & 0,3000 & 0,4000 & & \#Н/Д & & \#Н/Д & \#Н/Д \\
\hline $\begin{array}{l}\text { Stand. } \\
\text { Rejection }\end{array}$ & 0,0038 & 0,0046 & 0,0092 & 0,0638 & 0,1349 & & 0,2903 & & 0,7066 & 1,3051 \\
\hline $\begin{array}{l}\text { The sample } \\
\text { variance }\end{array}$ & 0,0000 & 0,0000 & 0,0001 & 0,0041 & 0,0182 & & 0,0843 & & 0,4993 & 1,7032 \\
\hline Excess & 2,9227 & 3,8688 & 1,8537 & 2,2752 & 2,0047 & & 1,3706 & & 0,1892 & 1,0974 \\
\hline Asymmetry & 1,7130 & 1,8533 & 0,0468 & 0,2262 & 0,0494 & & 1,1478 & & 0,2693 & 0,3950 \\
\hline Interval & 0,0100 & 0,0130 & 0,0210 & 0,2000 & 0,3200 & & 0,7900 & & 2,0500 & 3,9000 \\
\hline Minimum & 0,0100 & 0,0200 & 0,0400 & 0,2000 & 0,4000 & & 1,0100 & & 2,0700 & 5,1100 \\
\hline Maximum & 0,0200 & 0,0330 & 0,0610 & 0,4000 & 0,7200 & & 1,8000 & & 4,1200 & 9,0100 \\
\hline Total & 0,0770 & 0,1444 & 0,3010 & 1,7800 & 3,2800 & & 7,7500 & & 18,300 & 43,260 \\
\hline Account & 6,0000 & 6,0000 & 6,0000 & 6,0000 & 6,0000 & & 6,0000 & & 6,0000 & 6,0000 \\
\hline Maximum & 0,0200 & 0,0330 & 0,0610 & 0,4000 & 0,7200 & & 1,8000 & & 4,1200 & 9,0100 \\
\hline Minimum & 0,0100 & 0,0200 & 0,0400 & 0,2000 & 0,4000 & & 1,0100 & & 2,0700 & 5,1100 \\
\hline $\begin{array}{l}\text { Reliability level } \\
95.0 \%\end{array}$ & 0,0040 & 0,0049 & 0,0096 & 0,0669 & 0,1415 & & 0,3046 & & 0,7415 & 1,3696 \\
\hline $\begin{array}{l}\text { as a } \% \text { of the } \\
\text { average }\end{array}$ & $31 \%$ & $20 \%$ & $19 \%$ & $23 \%$ & $26 \%$ & & $24 \%$ & & $24 \%$ & $19 \%$ \\
\hline confidence interv & & 040 & 0,0049 & 0,0096 & 0,0669 & 0,141 & & 0,3046 & 0,7415 & 1,3696 \\
\hline $\begin{array}{l}\text { confidence interv } \\
\text { the normal distrib }\end{array}$ & $\begin{array}{l}\text { al of } \\
\text { sution }\end{array}$ & 031 & 0,0037 & 0,0073 & 0,0510 & 0,107 & & 0,2323 & 0,5654 & 1,0443 \\
\hline & & tween exp & ents $N^{o}$ & & & & Correla & ion, $\%$ & & \\
\hline & & ad 2 & & & & & $99,99 \%$ & & & \\
\hline Correlation & & nd 3 & & & & & $95,83 \%$ & & & \\
\hline (in pairs of lines) & & ind 4 & & & & & $90,11 \%$ & & & \\
\hline & & ind 5 & & & & & $96,29 \%$ & & & \\
\hline & & ind 6 & & & & & $99,47 \%$ & & & \\
\hline
\end{tabular}


Figure 3. Results of several (6) repeated tests under the most equal conditions (A) and approximation by the fifth degree polynomial of the $\mathrm{CO}$ oxidation reaction profile (mean values) in the presence of a $\mathrm{Pd} / \mathrm{Y}-\mathrm{Al}_{2} \mathrm{O}_{3}$

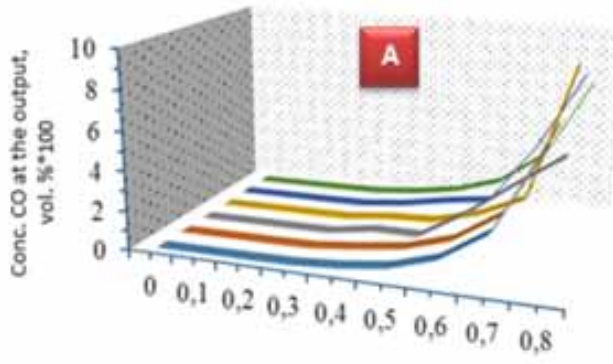

Volume of skipped $\mathrm{CO}, 1$

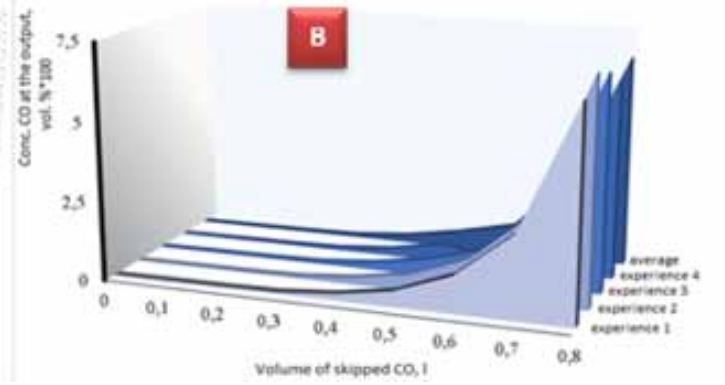

\section{The Permissible Error in Measurement of Activity}

It is not surprising that when studying nanocatalysts on polymer carriers with an increase in complexity by several orders of magnitude, we can talk about trends, but not about quantitative reproducibility. Typical data on the measurement of activity in the flow mode for a series of nanocatalysts deposited on the UVM and obtained under the same conditions.

As the presented data show, the values of the standard deviation can often exceed the value of the mathematical expectation itself. It is clear that the impossibility of improving the accuracy of quantitative measurement does not mean that it is impossible to study the phenomenon, but the method of studying is closer to those that are accepted for the study of biological and especially social objects, where the legal tolerance is also significant (Gumilev 1972).

Figure 4. Profile of the catalytic oxidation reaction with oxygen in the presence of a palladium catalyst deposited on chromium oxide ( $2 \%$ by weight $P d)$. Pulse mode.

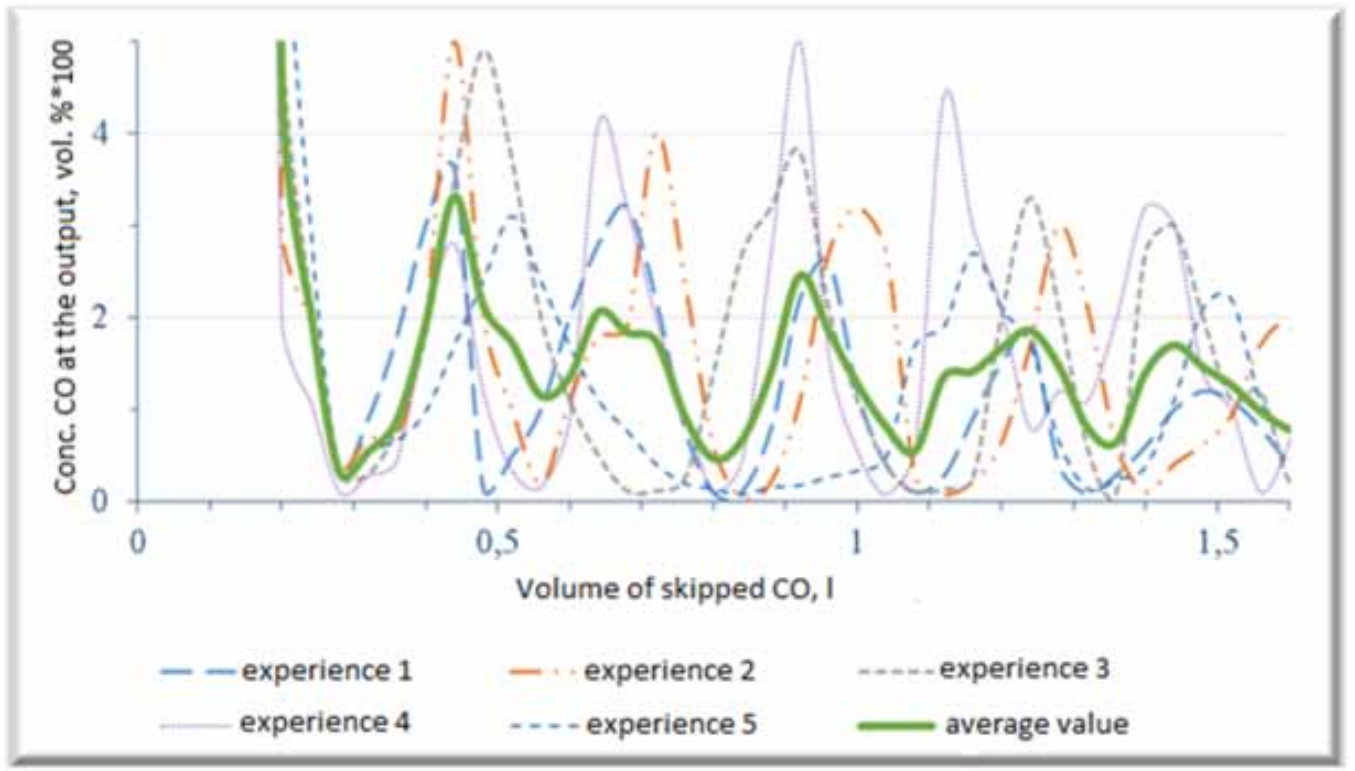


Table 3. Mathematical processing and descriptive statistics for repeated measurements of the activity of a palladium composite on $\mathrm{Cr}_{2} \mathrm{O}_{3}$ in the $\mathrm{CO}$ oxidation.

\begin{tabular}{|c|c|c|c|c|c|c|c|c|c|c|c|}
\hline $\begin{array}{l}\text { volume } \\
\text { of } \\
\text { skipped } \\
\mathrm{CO}, \mathrm{l}\end{array}$ & $\begin{array}{l}\text { Experience } \\
I\end{array}$ & $\begin{array}{l}\text { Experience } \\
2\end{array}$ & Experience 3 & $\begin{array}{l}\text { Experience } \\
4\end{array}$ & $\begin{array}{l}\text { Experience } \\
5\end{array}$ & $\begin{array}{l}\text { Average } \\
\text { value }\end{array}$ & $\begin{array}{l}\text { standard } \\
\text { deviation }\end{array}$ & \multicolumn{2}{|c|}{$\begin{array}{l}\text { confidence } \\
\text { intervals, } \\
\text { probable } 68 \%\end{array}$} & \multicolumn{2}{|c|}{$\begin{array}{l}\text { Confidence intervals of } \\
\text { norms, } \\
\text { probable } \\
95 \%\end{array}$} \\
\hline 0,16 & 40 & 58 & 12 & 31 & 44 & 37,000 & 17,029 & 8,639 & $23 \%$ & 14,927 & $37 \pm 8,64$ \\
\hline 0,2 & 4,8 & 3 & 5 & 2 & 8 & 4,560 & 2,295 & 1,164 & $26 \%$ & 2,012 & $4,56 \pm 1,16$ \\
\hline 0,24 & 2,1 & 2 & 2,2 & 1,1 & 3 & 2,080 & 0,676 & 0,343 & $16 \%$ & 0,593 & $2,08 \pm 0,34$ \\
\hline 0,28 & 0,4 & 0,41 & 0,3 & 0,11 & 0,38 & 0,320 & 0,125 & 0,063 & $20 \%$ & 0,110 & $0,32 \pm 0,06$ \\
\hline 0,32 & 0,9 & 0,7 & 0,3 & 0,28 & 0,55 & 0,546 & 0,265 & 0,134 & $25 \%$ & 0,232 & $0,546 \pm 0,13$ \\
\hline 0,36 & 1,8 & 0,7 & 0,8 & 0,45 & 0,67 & 0,884 & 0,528 & 0,268 & $30 \%$ & 0,463 & $0,884 \pm 0,27$ \\
\hline 0,4 & 3 & 2 & 1,8 & 1,9 & 0,98 & 1,936 & 0,719 & 0,365 & $19 \%$ & 0,631 & $1,936 \pm 0,36$ \\
\hline 0,44 & 3,6 & 5 & 3,5 & 2,8 & 1,7 & 3,320 & 1,207 & 0,612 & $18 \%$ & 1,058 & $3,32 \pm 0,61$ \\
\hline 0,48 & 0,15 & 2 & 4,9 & 1,2 & 2,4 & 2,130 & 1,771 & 0,899 & $42 \%$ & 1,552 & $2,13 \pm 0,9$ \\
\hline 0,52 & 0,5 & 1 & 3,7 & 0,34 & 3,1 & 1,728 & 1,560 & 0,791 & $46 \%$ & 1,367 & $1,728 \pm 0,79$ \\
\hline 0,56 & 1 & 0,2 & 2 & 0,16 & 2,4 & 1,152 & 1,023 & 0,519 & $45 \%$ & 0,897 & $1,152 \pm 0,52$ \\
\hline 0,6 & 2 & 1,1 & 1,1 & 0,88 & 1,7 & 1,356 & 0,472 & 0,239 & $18 \%$ & 0,414 & $1,356 \pm 0,24$ \\
\hline 0,64 & 2,8 & 1,8 & 0,5 & 4,1 & 1,1 & 2,060 & 1,426 & 0,723 & $35 \%$ & 1,250 & $2,06 \pm 0,72$ \\
\hline 0,68 & 3,2 & 1,9 & 0,12 & 3,2 & 0,77 & 1,838 & 1,397 & 0,709 & $39 \%$ & 1,224 & $1,838 \pm 0,71$ \\
\hline 0,72 & 2,2 & 4 & 0,12 & 2 & 0,41 & 1,746 & 1,564 & 0,793 & $45 \%$ & 1,371 & $1,746 \pm 0,79$ \\
\hline 0,76 & 0,8 & 2,4 & 0,25 & 1 & 0,2 & 0,930 & 0,891 & 0,452 & $49 \%$ & 0,781 & $0,93 \pm 0,45$ \\
\hline 0,8 & 0,1 & 0,6 & 1,4 & 0,11 & 0,14 & 0,470 & 0,561 & 0,284 & $61 \%$ & 0,491 & $0,47 \pm 0,28$ \\
\hline 0,84 & 0,12 & 0,04 & 2,7 & 0,45 & 0,08 & 0,678 & 1,142 & 0,579 & $85 \%$ & 1,001 & $0,678 \pm 0,58$ \\
\hline 0,88 & 0,8 & 0,22 & 3,2 & 2,7 & 0,16 & 1,416 & 1,433 & 0,727 & $51 \%$ & 1,256 & $1,416 \pm 0,73$ \\
\hline 0,92 & 2,2 & 1,1 & 3,8 & 5 & 0,18 & 2,456 & 1,960 & 0,994 & $40 \%$ & 1,718 & $2,456 \pm 0,99$ \\
\hline 0,96 & 2,6 & 2,7 & 2,1 & 1,6 & 0,27 & 1,854 & 0,988 & 0,501 & $27 \%$ & 0,866 & $1,854 \pm 0,5$ \\
\hline 1 & 1,2 & 3,2 & 1,1 & 0,55 & 0,34 & 1,278 & 1,134 & 0,575 & $45 \%$ & 0,994 & $1,278 \pm 0,58$ \\
\hline 1,04 & 0,4 & 2,7 & 0,4 & 0,08 & 0,49 & 0,814 & 1,066 & 0,541 & $66 \%$ & 0,934 & $0,814 \pm 0,54$ \\
\hline 1,08 & 0,11 & 0,28 & 0,11 & 0,56 & 1,7 & 0,552 & 0,668 & 0,339 & $61 \%$ & 0,585 & $0,552 \pm 0,34$ \\
\hline 1,12 & 0,28 & 0,08 & 0,14 & 4,4 & 1,9 & 1,360 & 1,859 & 0,943 & $69 \%$ & 1,630 & $1,36 \pm 0,94$ \\
\hline 1,16 & 0,9 & 0,22 & 0,25 & 3 & 2,7 & 1,414 & 1,343 & 0,681 & $48 \%$ & 1,177 & $1,414 \pm 0,68$ \\
\hline 1,2 & 1,5 & 0,64 & 2 & 2,1 & 2,1 & 1,668 & 0,626 & 0,318 & $19 \%$ & 0,549 & $1,668 \pm 0,32$ \\
\hline 1,24 & 1,8 & 1,7 & 3,3 & 0,8 & 1,7 & 1,860 & 0,902 & 0,457 & $25 \%$ & 0,790 & $1,86 \pm 0,46$ \\
\hline 1,28 & 0,4 & 3 & 2,1 & 1,2 & 0,66 & 1,472 & 1,074 & 0,545 & $37 \%$ & 0,941 & $1,472 \pm 0,54$ \\
\hline 1,32 & 0,09 & 2,1 & 0,58 & 1,1 & 0,14 & 0,802 & 0,832 & 0,422 & $53 \%$ & 0,729 & $0,802 \pm 0,42$ \\
\hline 1,36 & 0,3 & 0,6 & 0,11 & 2 & 0,24 & 0,650 & 0,776 & 0,394 & $61 \%$ & 0,680 & $0,65 \pm 0,39$ \\
\hline 1,4 & 0,6 & 0,11 & 2,7 & 3,2 & 0,38 & 1,398 & 1,438 & 0,730 & $52 \%$ & 1,261 & $1,398 \pm 0,73$ \\
\hline 1,44 & 1 & 0,41 & 3 & 3 & 1,1 & 1,702 & 1,214 & 0,616 & $36 \%$ & 1,064 & $1,702 \pm 0,62$ \\
\hline 1,48 & 1,2 & 0,62 & 2 & 1,4 & 2,1 & 1,464 & 0,608 & 0,308 & $21 \%$ & 0,533 & $1,464 \pm 0,31$ \\
\hline 1,52 & 1,1 & 0,94 & 1,1 & 1 & 2,2 & 1,268 & 0,525 & 0,267 & $21 \%$ & 0,461 & $1,268 \pm 0,27$ \\
\hline 1,56 & 0,8 & 1,7 & 1,2 & 0,11 & 1,1 & 0,982 & 0,585 & 0,297 & $30 \%$ & 0,513 & $0,982 \pm 0,3$ \\
\hline 1,6 & 0,4 & 1,9 & 0,22 & 0,65 & 0,77 & 0,788 & 0,657 & 0,334 & $42 \%$ & 0,576 & $0,788 \pm 0,33$ \\
\hline 1,64 & 0,04 & 1,1 & 0,13 & 1,7 & 0,62 & 0,718 & 0,694 & 0,352 & $49 \%$ & 0,608 & $0,718 \pm 0,35$ \\
\hline 1,68 & 0,05 & 0,7 & 0,11 & 1 & 0,55 & 0,482 & 0,402 & 0,204 & $42 \%$ & 0,352 & $0,482 \pm 0,2$ \\
\hline
\end{tabular}


Table 4. Activity in the reaction of low-temperature oxidation of $\mathrm{CO}$ in the presence of nanocatalysts on various carriers. The series were synthesized under the same conditions.

\begin{tabular}{|c|c|c|c|}
\hline \multicolumn{2}{|l|}{$\begin{array}{l}\text { Carrier - carbon fiber } \\
\text { "Carbopon-Active" }\end{array}$} & \multicolumn{2}{|c|}{ Carrier - polypropylene mats } \\
\hline Cipher series & Activity, mol/l $* s * g$ & Cipher series & Activity, $m o l / l * s^{*} g$ \\
\hline $16-U-112$ & 0,7 & $15-\mathrm{P}-14$ & 0,5 \\
\hline $16-U-118$ & 14 & 15- P - 27 & 0,2 \\
\hline 16- $U-119$ & 3 & 15- P-93 & 0,7 \\
\hline 16- $U-129$ & 0,3 & $15-\mathrm{P}-121$ & 0,01 \\
\hline $16-U-130$ & 8 & 16- P-17 & 0,02 \\
\hline 16- $U-131$ & 4,2 & 16- P -23 & 0,11 \\
\hline 16- $U-135$ & 4 & $16-\mathrm{P}-35$ & 0,14 \\
\hline 16- $U-143$ & 7 & $16-\mathrm{P}-36$ & 7 \\
\hline 16- $U-157$ & 1,7 & $16-\mathrm{P}-37$ & 5 \\
\hline 16- $U-208$ & 1,3 & $16-\mathrm{P}-38$ & 1,9 \\
\hline 16- $U-229$ & 1 & $16-P-59$ & 0,1 \\
\hline 16- $U-260$ & 0,9 & 16- P -64 & 0,9 \\
\hline the average value, $\mathrm{mol} / 1 * \mathrm{~s} * \mathrm{~g}$ & 3,8 & & 1,4 \\
\hline Stand. Rejection & 4,1 & & 2,3 \\
\hline
\end{tabular}

Thus, the study of nanocatalysts during autocatalytic processes is informative using calculated parameters due to the change in instantaneous activity over time. These parameters can serve as selfoscillation indicators - frequency, period, and also averaged total characteristics.

\section{EXPERIMENTAL}

\section{Objects of Investigations}

Drawing catalysts comprising platinum metals - palladium and platinum - as active ingredient has been investigated. Fiber polymers - polypropylene fiber polyacrylonitrile, carbon fibers, low modulus carbon fibrous materials obtained by carbonization and subsequent activation of mats from "Mtilon-M", copolymers of polyacrylonitrile and hydrocellulose were used as bearers.

\section{Subjects and Methods}

Catalytic activity is dependent on $\mathrm{CO}$ concentration in the gas-air mixture at room conditions (Jiang et al., 2020). The rms-diameter and coefficient of polydispersity of nanoparticles (Mukhamediev et al., 2015) were measured via electronic microscopy.

\section{CONCLUSION}

Autocatalytic processes require a special approach to comparative study. One of the informative methods is the comparison of parameters when measuring the instantaneous characteristics of the process - catalytic activity at a given time and dimensional boundaries of functionality, which can periodically shift during the formation of hypercycles. Using the example of the catalytic oxidation of $\mathrm{CO}$ in the presence of palladium-containing nanoparticles, it is shown that this approach can 
provide sufficient reliability of the results obtained. It is shown also that the study of the behavior of nanocatalysts during the formation of hypercycles is informative using the calculated generalized parameters of the process. 


\section{REFERENCES}

Anwar, W., \& Khitab, A. (2019). Nanotechnology From Engineers to Toxicologists: Risks and Remedial Measures. [IJANR]. International Journal of Applied Nanotechnology Research, 4(2), 1-25.

Bol'shakov, A. M., Sergeeva, O. V., Minin, V. V., \& Bol'shakova, L. D. (2001). Oxygen Spillover in the Conversion of $\mathrm{NO}$ on a Pd-Co/ $\gamma-\mathrm{Al} 2 \mathrm{O} 3$ Catalyst. Theoretical and Experimental Chemistry, 37(1), 89-91. doi:10.1023/A:1010449308300

Casañola-Martin, G. M., \& Pham-The, H. (2019). Machine Learning Applications in Nanomedicine and Nanotoxicology: An Overview. International Journal of Applied Nanotechnology Research, 4(1), 1-7. doi:10.4018/IJANR.2019010101

Gorovoy, Y. M. (2018). Specific properties of complex systems described by nonequilibrium thermodynamics. Research, physical models and mechanisms of action of weak factors at the molecular and cellular level of the organization of biological objects, 27. http://www.biophys.ru/archive/congress-2018.pdf\#page=27

Gumilev, L. N. (1972). Art and ethnos. Decorative Art of the USSR, 1, 12.

Gusev, A. I., \& Rempel, A. A. (2004). Nanocrystalline materials. Cambridge Int Science Publishing.

Jiang Li, X., Liu, L., Hua, J., Wang, Q. E., \& Xie, G. (2020). Size-dependent catalytic activity of cobalt phosphides for hydrogen evolution reaction. Journal of Energy Chemistry, 43, 121-128.

Kalgin, K. (2011). Domain specific language and translator for cellular automata models of physico-chemical processes. In International Conference on Parallel Computing Technologies (pp. 166-174). Springer. doi:10.1007/978-3-642-23178-0_14

Kempkes, S. N., Slot, M. R., Freeney, S. E., Zevenhuizen, S. J., Vanmaekelbergh, D., Swart, I., \& Smith, C. M. (2019). Design and characterization of electrons in a fractal geometry. Nature Physics, 15(2), $127-131$. doi:10.1038/s41567-018-0328-0 PMID:30886641

Kureychik, V. V., Kureychik, V. M., \& Sorokoletov, P. V. (2007). Analysis and review of evolution models. Proceedings of the Russian Academy of Sciences. Theory and Control Systems, 5, 114-126. https://elibrary.ru/ item.asp?id $=9534167 \&$

Mukhamediev, M. G., \& Rakhimov, T. K. (2015). Complete Removal Of Carbon Monoxide In The Presence Of Nanocatalysts. Ecol. Chemistry, 24(2), 68-76. https://www.elibrary.ru/item.asp?id=24315414

Rakhimov, T. K., \& Mukhamediev, M. G. (2014). Palladium containing composite nanosystems in lowtemperature co oxidation: Decisive influence of the support to the reactions' mode. Composite Materials Uzbekistan Sci. and Tech., 2, 8-11.

Rakhimov, T. K., \& Rakhmanova, G. S. (2019). Calculation of active fractions sizes in supported nanocrystals. Computational Nanotechnology, (1), 44-52.

Rasulev, B., Watkins, M., Theodore, M., Jackman, J., \& Leszczynski, J. (2012). Structures and Stabilities: Quantum-Chemical Study of Aun $(n=2-2016)$ Nanoclusters by Extended Huckel and DFT Approaches. Nanoscience \& Nanotechnology-Asia, 2(1), 2-10.

Shulgina, T. A. (2015). Study of the antimicrobial properties of dispersed systems based on silver and copper nanoparticles and substantiation of the prospects for their use (Doctoral dissertation). Shulgina, TA.

Von, N. J., \& Burks, A. W. (1996). Theory of self-reproducing automata. University of Illinois.

Zhizhin, G. V. (2019). The Geometry of Higher-Dimensional Multi-Shell Clusters With Common Center and Different Centers: The Geometry of Metal Clusters With Ligands. [IJANR]. International Journal of Applied Nanotechnology Research, 4(2), 45-65. 
International Journal of Applied Nanotechnology Research

Volume 5 • Issue 1 • January-June 2020

Zulayho Asanaliyevna Smanova has a Doctor of Science and is a professor. They are the head of the Department of Analytical Chemistry.

Tokhir Rakhimov has a Doctor of Science and is an assistant professor.

Muxtarjan Mukhamediev has a Doctor of Science and is a professor.

Dilfuza Gafurova has a Doctor of Science and is an assistant professor.

Dilbar Shaxidova has a PhD. 